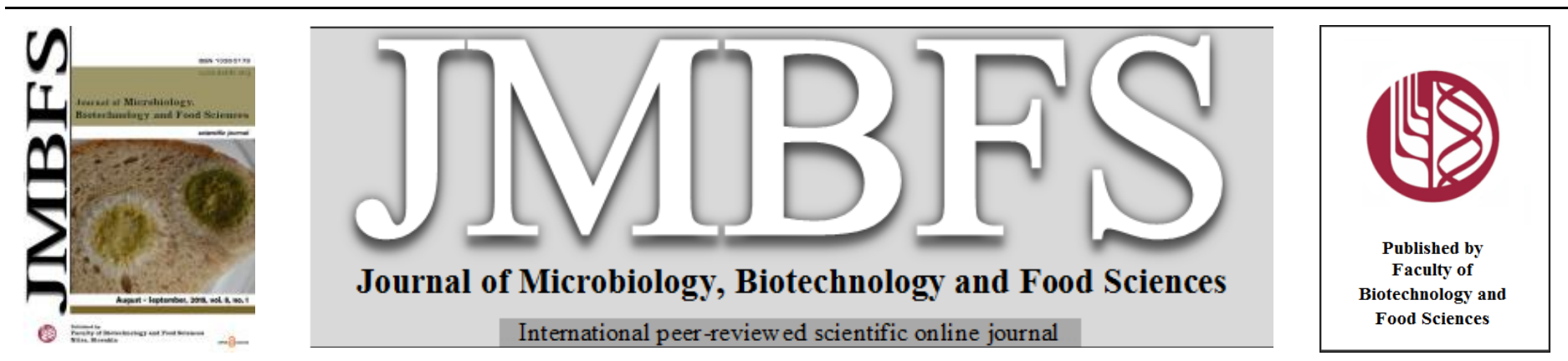

\title{
IN-SILICO STUDIES OF SOME NATURAL, SYNTHETIC AND SEMI-SYNTHETIC ANTIFUNGAL DRUGS FOR THEIR MULTI-TARGETING NATURE
}

\author{
Neelabh, Karuna Singh*
}

Address(es): Karuna Singh,

Department of Zoology, Mahila Mahavidyalaya, Banaras Hindu University, Varanasi-221005.

*Corresponding author: karunasingh5.bhu@ mail.com

doi: 10.15414/jmbfs.2018.8.1.711-716

\section{ARTICLE INFO}

Received 6. 4. 2018

Revised 14. 5. 2018

Accepted 3. 7. 2018

Published 1. 8. 2018

Regular article open $\mathcal{O}$ access

\section{ABSTRACT}

Research has shown that drugs or therapeutic agents which are directed at a particular target often undergo a reduction in efficacy, undesired safety profiles, compensatory and neutralizing effects, anti-target and counter target activities and also resistance against the drug. Proper utilization of multiple targets can lead to a perfect blend between the efficacy and safety when compared against singletargeted drug design. The authors have utilized this concept in case of the antifungal drugs which generally act against one of the targets amongst chitinase, chitin synthase, 1, 3 beta glucan synthase and lanosterol $14 \alpha$-demethylase. Henceforth, the present study is an attempt to screen the known drugs for their multi-targeting nature, and to compare natural product based drugs with semi-synthetic and synthetic drugs in-silico.

In the present study, eleven (7 synthetic and 4 natural) drugs namely Allosamidine, Methylxanthine, Acetozolamide, Nikkomycin Z, Polyoxin L, Caspofungin, Fluconazole, Argifin, Obovatol, Papulacandin and Ro-091470 have been chosen to study their effect against different targets.

This exciting and unique in-silico study provides insight that some drugs can function equally good against all targets, while some have a better efficiency against a different target than the known one. All four studied natural product based drugs are found to be good at multi-targeting. All the drugs that were shown to have a good multi-targeting efficiency bind at the same region where the known drugs against that target bind. Furthermore, lanosterol $14 \alpha$-demethylase is found to be the best target amongst all the aforesaid fungal targets.

Keywords: Multi-targeting; In-silico; FireDock; Binding Energy; Drug designing

\section{INTRODUCTION}

Despite the mammoth strides taken in the screening of the drugs and rational drug designing, result in the form of number of successful drugs and discovery of novel targets is not satisfactory (Korcsmáros et al., 2007). Till date we have not been able to find tenable and broad spectrum therapeutic options against many life threatening diseases. The need of finding new therapeutic options intensifies more when it comes to fungi, because fungi are similar to humans and the drugs designed against them are likely to cause side-effects in human beings as well (Neelabh et al., 2018, Neelabh and Singh, 2018 ).

For obtaining improved results in the field of drug development there is a need of modifying the approach we have towards drug designing or development. The goals or the procedure of drug development can be summarized in figure 1 .

In other words, it can be said that the chemical library of the potential therapeutic compounds is screened exhaustively through different computational as well as wet lab methods (Csermely et al., 2005). Furthermore, the best binder is obtained by evaluating the interaction between the ligand and the target (figure 2). But as already mentioned, this model lags far behind in the treatment of diseases such as cancer, AIDS, neurological, cardiovascular, mycoses etc.

Failure in the treatment of life threatening diseases can be attributed to numerous reasons, primary amongst them is the "single-target" or "single-hit" against which the drug is being targeted. Unfortunately, this approach is not compatible with the modern day micro-organisms which have a capacity to fast become resistant to any specific drug. Moreover, studies on biological systems and the experience gained by clinical practices suggests that focussing on a single target might provide up regulation or down regulation of the target but might not be able to provide the desired result to the biologic body as a whole (figure $3 \mathrm{a}$ and figure $3 b$ ).

Additionally, the Networking model says that it is much more fruitful to partially inhibit large number of small targets rather than completely inhibiting a single large target (Tang et al., 2013).

Multi-targeting activity of the compounds can be easily seen in nature. For instance, snake venom and spider venoms utilize multiple targets in order to exert their effects. Similarly, plants use factors having effect on multiple targets that defends them against any pathogenic attack. Traditional treatments also comprise of the multi component extracts which are directed towards different targets (Csermely et al., 2005)

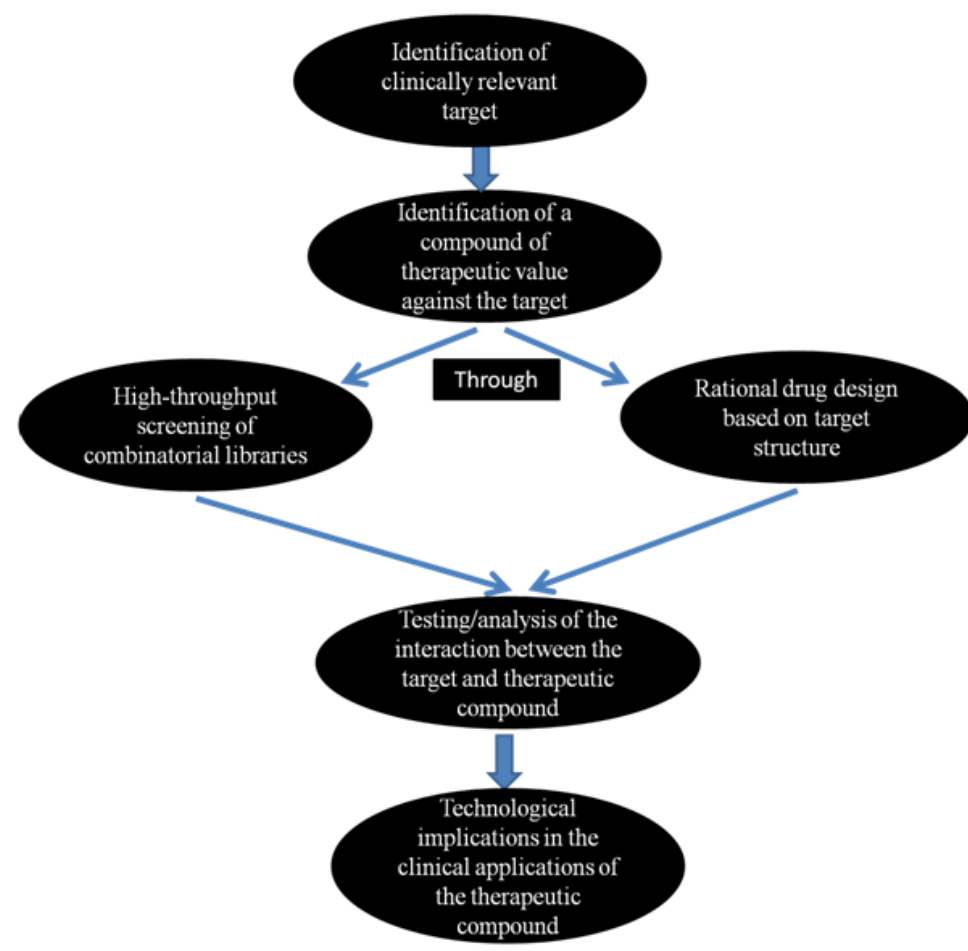

Figure 1 The goal of drug development 


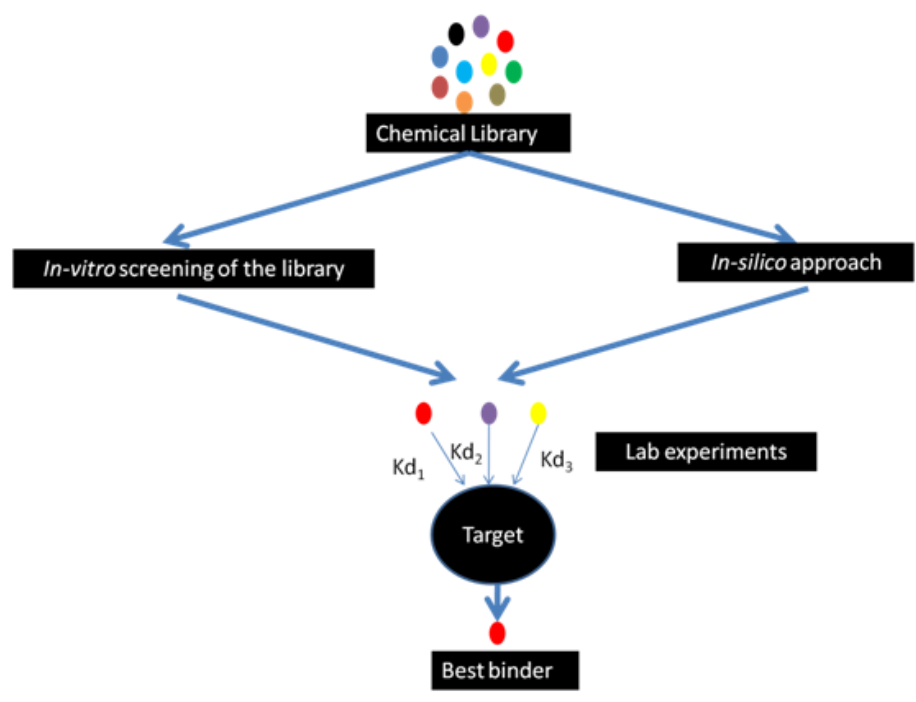

Figure 2 The currently used model for drug development. The in-vitro and insilico approaches utilize the chemical library and find suitable ligands for the target. Then through the various wet lab techniques the best binder to the target is determined.
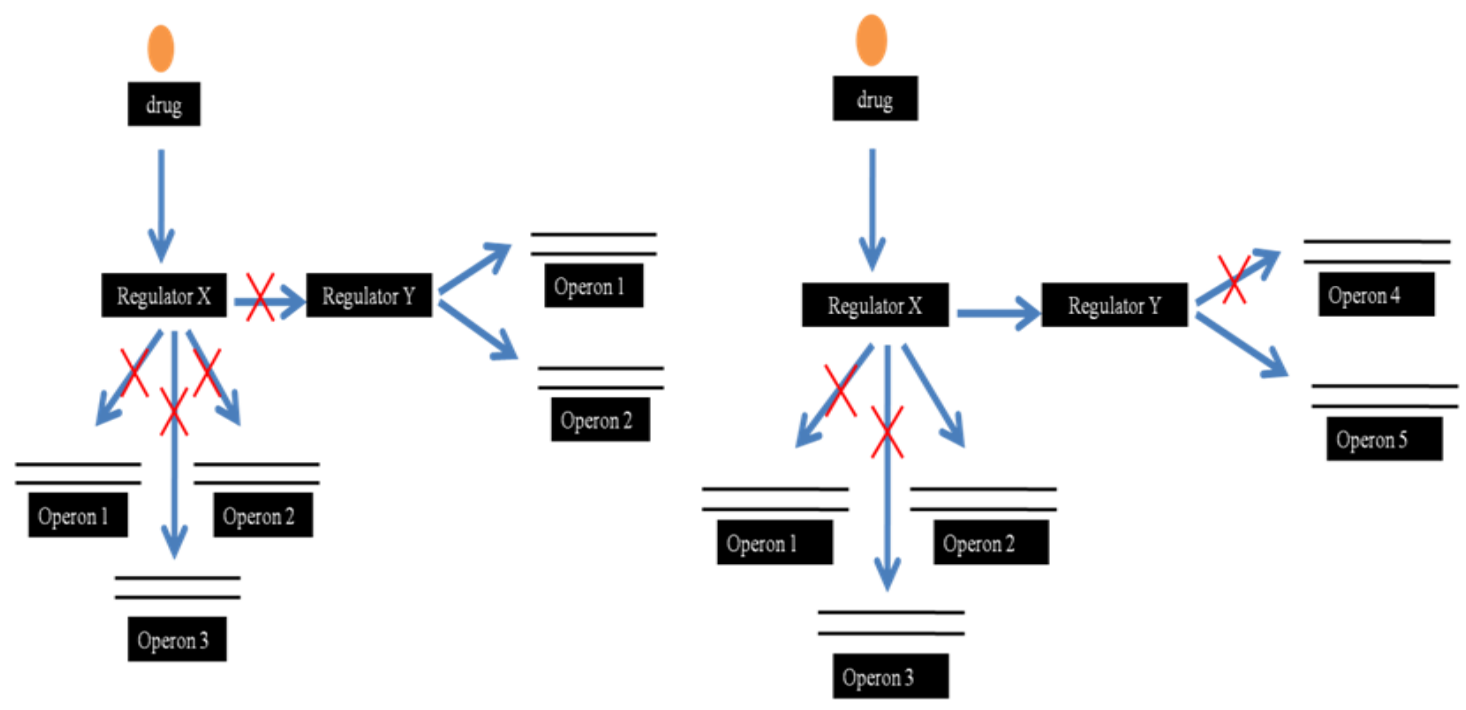

Figure 3 a) Complete inactivation of the single target (regulator $\mathrm{X}$ ) has been shown which is the current model of the single target drug design $\mathrm{b}$ ) The partial inactivation of multiple targets (regulators $\mathrm{X}$ and $\mathrm{Y}$ ), is the model that needs to be followed for producing efficient multi- target drugs.

Table 1 Drugs and their respective known targets

\begin{tabular}{l} 
Drugs tested \\
\hline Argifin(Natural) \\
http://www.drugbank.ca/drugs/DB03632
\end{tabular}

Allosamidine

http://www.drugbank.ca/drugs/DB04628

Methylxanthine

http://www.chemspider.com/Chemical-Structure.72464.html

Acetozolamide

http://www.drugbank.ca/drugs/DB00819

Obovatol (Natural)

http://chem.sis.nlm.nih.gov/chemidplus/rn/83864-78-2

Nikkomycin Z

http://www.chemicalbook.com/ChemicalProductProperty_EN_CB0767000.html

Chitin synthase

Polyoxin L

http://pubchem.ncbi.nlm.nih.gov/compound/100013\#section=Top

Papulacandin (Natural)

http://pubchem.ncbi.nlm.nih.gov/compound/6450326

Caspofungin

http://www.drugbank.ca/drugs/DB00520

Ro-091470 (Natural)

http://www.guidechem.com/dictionary/en/135357-96-9.html

Fluconozole

http://www.drugbank.ca/drugs/DB00196

Lanosterol $14 \alpha$-demethylase PDB ID: 4 LXJ 
The current manuscript focusses on the multi-targeted drug designing against mycological diseases. The authors have chosen 4 main target enzymes chitinase, chitin synthase, 1,3-beta-glucan synthase and lanosterol $14 \alpha$-demethylase which are main targets of currently available antifungals. Chitinase is a chief enzyme which apart from fungal cell wall degradation and remodelling also performs exogenous chitin decomposition in fungi (Hartl et al., 2012) while chitin synthase is another important enzyme which governs the synthesis of chitin in the fungal cell wall (Henar et al., 1998). 1,3-beta-glucan synthase is an enzyme having multiple subunits and is responsible for fungal cell wall formation, division, septum deposition and ascospore wall assembly (Liu and Balasubramanium, 2001). Lanosterol $14 \alpha$-demethylase is a key enzyme that mediates the conversion of lanosterol into ergosterol which is a key component of the fungal cell membrane (Becher and Wirsel, 2012).

In the present manuscript the grouping of the drugs have been made in such a way that each group comprises of a natural antifungal and synthetic or semi synthetic antifungals (Table 1 )

In the first group of table 1, Argifin is the natural drug and all the other drugs in that group are non natural, synthetic or semi synthetic in nature. Similarly, Obovatol (Hwang et al., 2002), Papulacandin and Ro-091470 (Aoki et al., 1993) are the natural members of the groups having targets as chitin synthase, 1,3-betaglucan synthase and lanosterol $14 \alpha$-demethylase respectively.

\section{MATERIAL AND METHODS}

The different fungal targets viz. chitinase, chitin synthase, 1,3-beta-glucan synthase and lanosterol $14 \alpha$-demethylase have been docked upon by different antifungals such as Argifin, Papulacandin, Polyoxin L, Obovatol, Allosamidine, Acetozolamide, Methylxanthine, Ro-091470, Fluconazole, Caspofungin and Nikkomycin. The authors could not find the suitable structures of 1,3-beta-glucan synthase and chitin synthase, therefore these structures were modelled through Phyre $^{2}$ software and were utilized for docking. A brief outline for the above process has been provided in figure 4 .

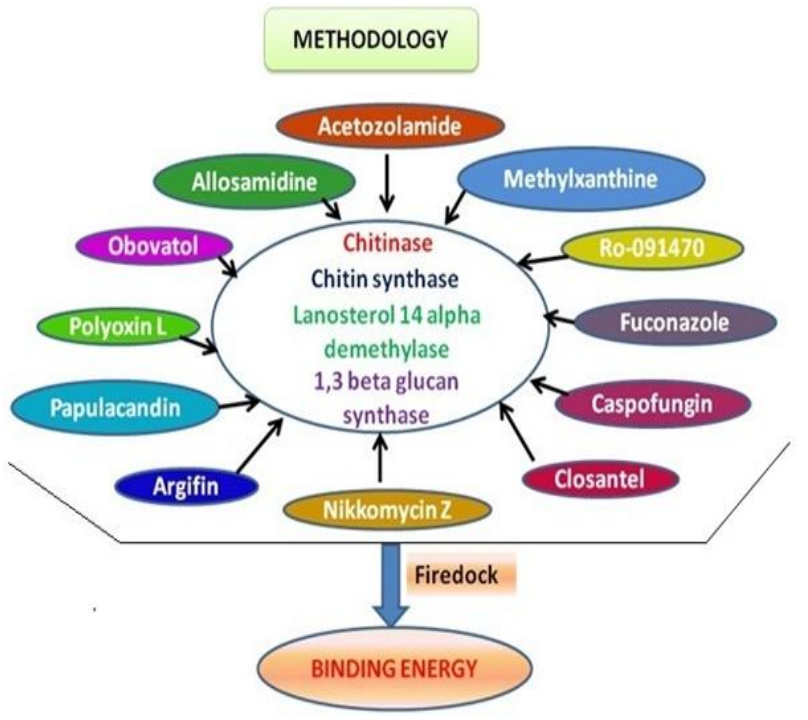

Figure 4 An outline of the methodology employed.

The authors have chosen natural, synthetic as well as semi-synthetic drugs that are specifically known to act on a particular target and further tested them for having multi targeting nature through FireDock which calculates the binding energy of the antifungal against the target. This binding energy is the indicator of the affinity of antifungal towards its target.

\section{FireDock}

FireDock is an efficient and reliable method utilized for refinement and rescoring for rigid-body docking predictions. FireDock functions on the principle of "coarse refinement". Coarse refinement comprises of side chain optimization and rigid body minimization (Mashiach et al., 2008; Neelabh et al., 2015)

\section{RESULTS}

Present manuscript is an attempt to screen the currently used antifungals for their multi targeting efficiency. Due to the unavailability of the the structures for 1,3 beta-glucan synthase and chitin synthase they have been modeled through Phyre web server and shown in figure $5 \mathrm{a}$ and figure $5 \mathrm{~b}$. The sequences utilized for the homology modeling have been mentioned in table 2 .
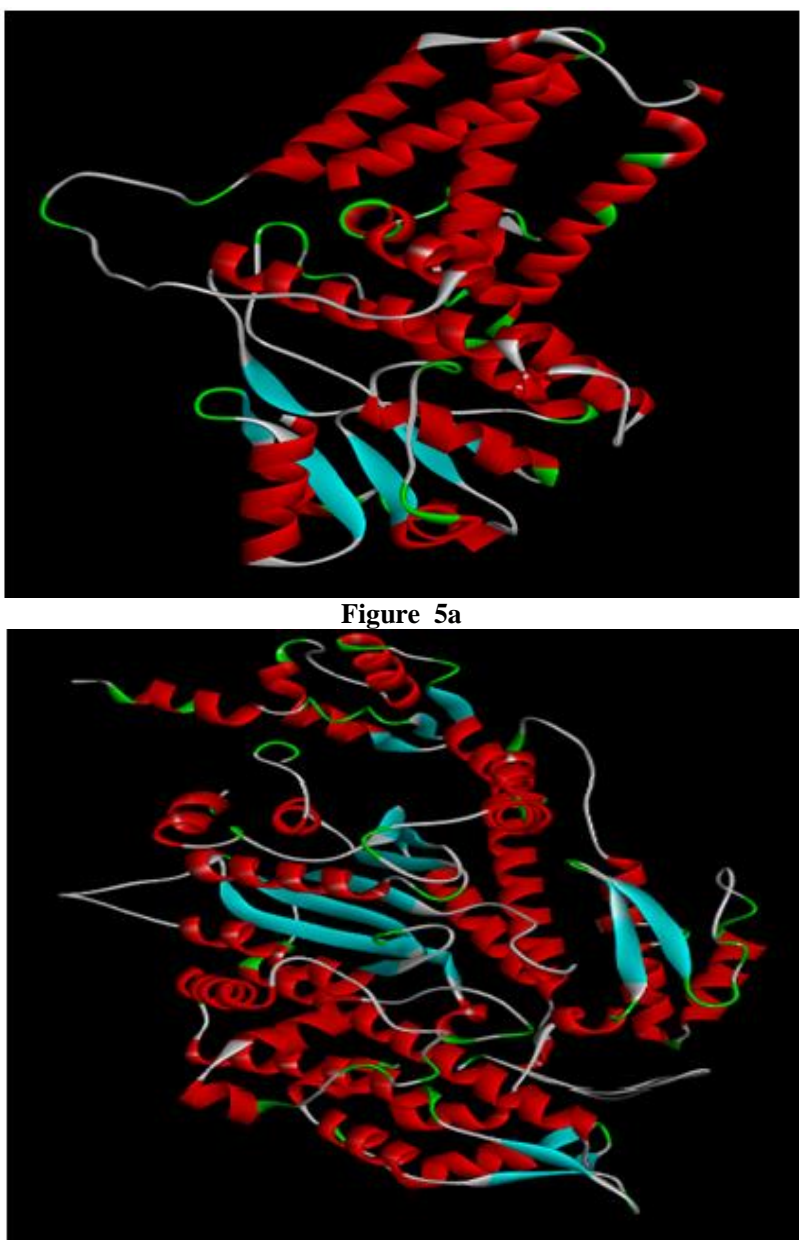

Figure 5b

Figure 5 Modelled structures of a)1,3 beta glucan synthase b) Chitin synthase both visualized by Discovery Studio visualization software.

Further, validity of both the models was ascertained through RAMPAGE webserver and $93.4 \%$ residues were found in favoured region, $3.5 \%$ were found in allowed region and $3.2 \%$ in the outlier region for 1,3-beta-glucan synthase whereas $89.7 \%$ residues were found in favoured region, $7.6 \%$ were found in allowed region and $2.7 \%$ in outlier region (http://mordred.bioc.cam.ac.uk/ rapper/rampage.php). These structures have also been submitted to Protein model database (https://bioinformatics.cineca.it/PMDB/).

Table 2 Sequences utilized for 1,3-beta-glucan synthase and chitin synthase for homology modelling

\begin{tabular}{|c|c|}
\hline Target & Sequence \\
\hline 1,3 beta glucan synthase & $\begin{array}{l}\text { GKSDNQNHAIIFYRGEYLQLIDANQDNYLEECLKIRNVLGEFFAKFPVAILGAREYIFSENIGILGDIAAGKEQTFGTLAARSLSYIGGKLHYGHPD } \\
\text { FLNAIYMNTRGGVSKAQKGLHLNEDIFAGMLAFGRGGRIKHSEYYQCGKGRDLGFGTILNFQTKIGTGMGEQMLSREYYYLGTQLPIDRFLTFY } \\
\text { YGHPGFHINNILVMMSVQVMLALVFLGTLNKQLTVSIFIVFWIAFVPLFVQELTERGTGRAILRLCKHFLSLSPVFEVFSTQIYMHSILNDLTFGG } \\
\text { ARYIATGRGFATTRISFSILYSRFAGPSIYLGIRTLVILLFVTLTVWVPHLIYFWITVVGLCVA }\end{array}$ \\
\hline Chitin synthase & $\begin{array}{l}\text { VTDLSPYSYLPIDGEESLLRYVEEKKKLEEPHVFQLALGAYYNMRRTGQDQVIIASGPTGSGKSELKRLAIEAITQVSLANPGKKGSKIGLQVSSA } \\
\text { EFILKCFGNAHTLSNDEASRFGTYTELQFNERGRLEGLKTIVYYFERSRVSQVPINGERNFHAFYYLVSGAPEEERNFLKLGDVSDYRYLNCRVR } \\
\text { RVGVDDRHRYSQLRQAFKMIGISSRLIAQIFQLLASILHIGNLRFSPSDGIQEGASVINIDTLDTVAEFLGVHSESLAEIFSLKTILVRKEVCTTFLGP } \\
\text { EQAEQVRDELARTLYSLLFSWLNEHINTRLCKDSFGSFIALVDLPGIQRNSGSMGLNSVDQFCLNFAAEKMHNWVLHRIHETRQEAEAERLLI } \\
\text { SRVPYFDNSECLGMLSNPRGGLISVIDDLSQKKRSESNLLESLGKRFHNHPSMSISPQGNRSSASFTINHYDGPVTYSTSNFLERNANETSTDIILLL } \\
\text { RGSSNPFIKGLFGMLVPVSEEGGEEASDFQVGGGNDESSPELHCIAGQHWAAVDSLLSFDQTQTWYIFALRPNDSQLPFQFDLRSMKQQVRS } \\
\text { FGLVEMAQQLQTSWEVRLPHKEACERYNEELVYRGIPEGTGDVERLRDLKRLMSLNDADMGIGLQRVFLSNNLFHFLEDRLRAKEPGEQHAYE }\end{array}$ \\
\hline
\end{tabular}


All the target proteins have an active site on which the drugs act and modify the function of the protein. The active site of the target proteins has been determined by the CASTp server and further docking of drugs on their respective known targets has been performed with the help of FireDock (figure 6).

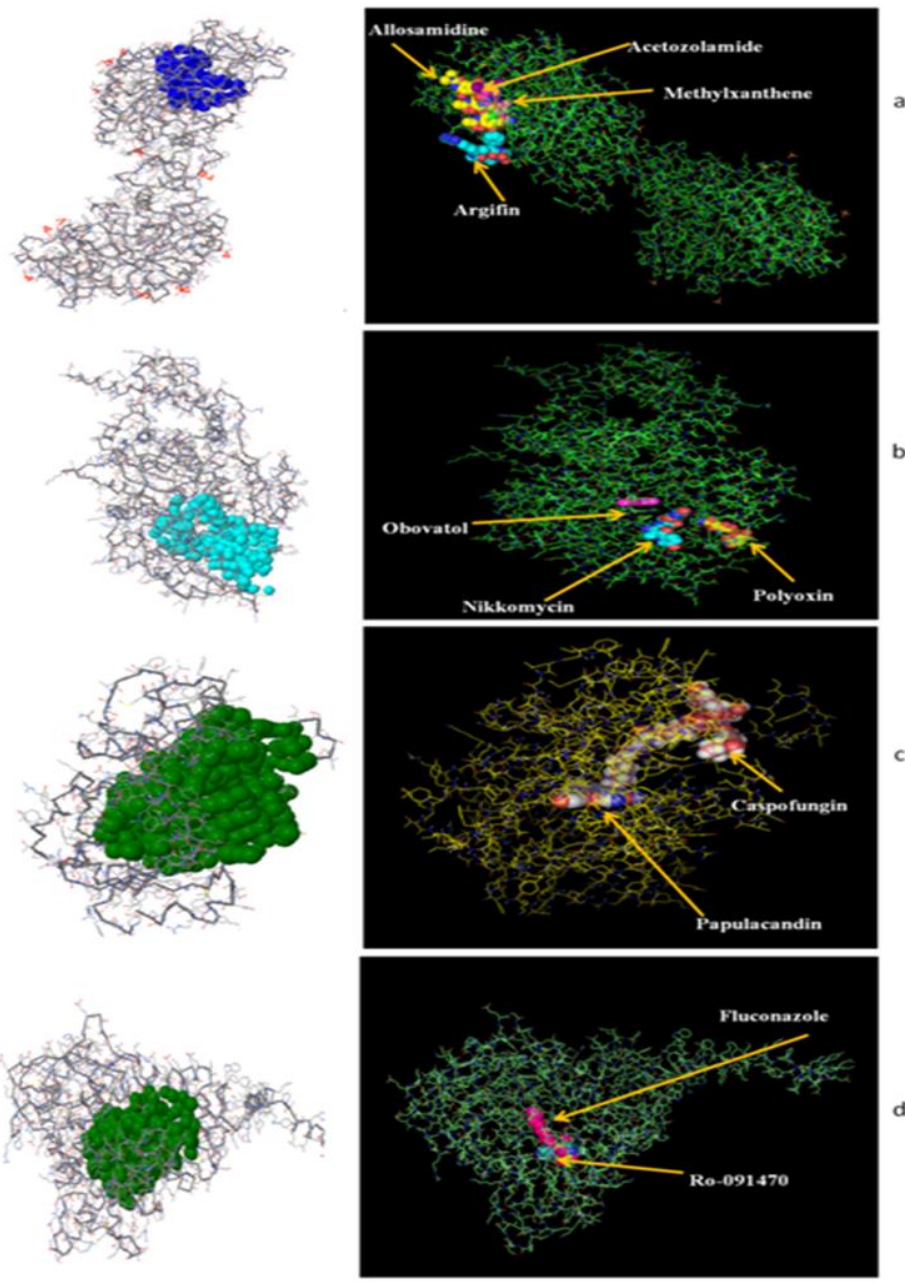

Figure 6 Active sites of the target proteins and drugs docked at it. a) chitinase docked with Argifin, Allosamidine, Methylxanthine, Acetozolamide b) chitin synthase docked with Obovatol, Nikkomycin and Polyoxin c) 1,3-beta-glucan synthase docked with Papulacandin and Caspofungin d) lanosterol $14 \alpha-$ demethylase docked with Ro-091470 and Fluconazole.

The binding energy of Argifin, Methylxanthine, Acetozolamide, and Allosamidine against chitinase has been depicted in table 3 which shows that Allosamidine has the highest binding energy against its known target chitinase. On the other hand Argifin, a natural antifungal having the same target, has a greater multi-targeting efficiency than the other synthetic and semi synthetic drugs in its group. Therefore, it could be a better drug in comparison to the others in its group. The highest binding energy of Argifin has been obtained against lanosterol $14 \alpha$-demethylase.

Table 3 Results of Argifin, Methylxanthine, Acetozolamide and Allosamidine against Chitinase (known target) and others obtained from FireDock.

\begin{tabular}{lcccc}
\hline Drug & $\begin{array}{c}\text { Chitinase } \\
\text { (Known) }\end{array}$ & $\begin{array}{c}\text { Chitin } \\
\text { Synthase }\end{array}$ & $\begin{array}{c}\mathbf{1 , 3} \text { beta } \\
\text { glucan } \\
\text { synthase }\end{array}$ & $\begin{array}{c}\text { Lanosterol 14 } \\
\boldsymbol{\alpha} \text {-demethylase }\end{array}$ \\
\hline Argifin & -28.59 & -25.53 & -74.06 & -74.74 \\
Methylxanthine & -25.42 & -23.76 & -50.05 & -53.84 \\
Acetozolamide & -28.09 & -21.56 & -41.34 & -37.92 \\
Allosamidine & -29.99 & -23.89 & -55.90 & -63.88 \\
\hline
\end{tabular}

On examining the best docked structure of Argifin against lanosterol $14 \alpha$ demethylase it was observed that Argifin was also binding in the same area or active site where all the other known drugs against lanosterol 14 alpha demethylase (Ro-091470 and Fluconazole) docked, and thus can be assumed to show activity against the aforesaid protein (figure 7b).
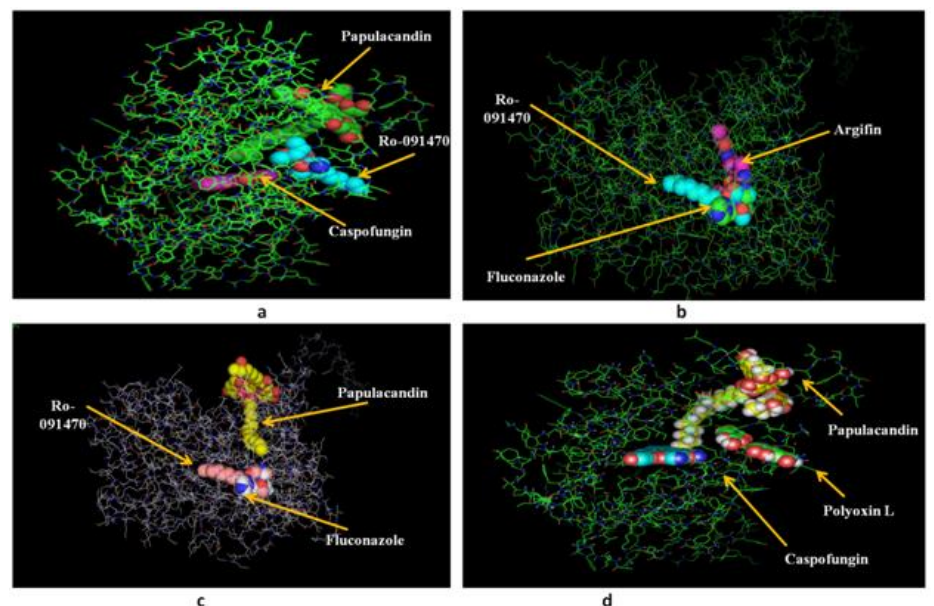

Figure 7 Best docked structures. a) Ro-091470 binds 1,3-beta-glucan synthase where the drugs having the known activity (Caspofungin and Papulacandin) against this target bind $b$ ) Argifin binds to the same region or active site of lanosterol $14 \alpha$-demethylase where the drugs having the known activity (Fluconazole, Ro-091470) against the aforesaid target bind c) Papulacandin binds to the same region or active site of lanosterol $14 \alpha$-demethylase where the drugs having the known activity (Fluconazole, Ro-091470) against this target bind d) Polyoxin $\mathrm{L}$ binds to the same region or active site of 1,3-beta-glucan synthase where the drugs having the known activity (Papulacandin and Caspofungin) against the said target bind.

Binding energies of Obovatol, Nikkomycin and Polyoxin L have been obtained against their known target chitin synthase as well as other targets (Table 4).

Table 4 Results of Obovatol, Nikkomycin Z and Polyoxin L against chitin synthase (known target) and others obtained from FireDock.

\begin{tabular}{lcccc}
\hline Drug & $\begin{array}{c}\text { Chitin } \\
\text { synthase } \\
\text { (Known) }\end{array}$ & Chitinase & $\begin{array}{c}\mathbf{1 , 3} \text { beta glucan } \\
\text { synthase }\end{array}$ & $\begin{array}{c}\text { Lanosterol 14 } \\
\boldsymbol{\alpha} \text {-demethylase }\end{array}$ \\
\hline Obovatol & -23.94 & -27.70 & -40.96 & -43.63 \\
Nikkomycin & -21.86 & -22.79 & -58.83 & -65.68 \\
Z & -43.68 & -38.71 & -78.24 & -67.27 \\
Polyoxin L & - &
\end{tabular}

This gives us an insight that Polyoxin $\mathrm{L}$ has the highest binding energy amongst members of its group against their known target chitin synthase. Additionally, it can be observed that Polyoxin L has high binding energies against all the other targets as well, therefore, it can be assumed to have the highest multi-targeting efficiency in its group. The highest binding energy of Polyoxin $\mathrm{L}$ is found against 1,3 beta glucan synthase. On analysis of its best docked structure against 1,3beta-glucan synthase (figure 7d) it can be concluded that it binds in the same area or the active site of the 1,3-beta-glucan synthase where all the other members of the 1,3-beta-glucan synthase interacting drugs (Caspofungin and Papulacandin) bind.

On analysis of table 5, it portrays the binding energies of Caspofungin and Papulacandin against their known targets 1,3-beta-glucan synthase and other targets as well. Caspofungin has a higher binding energy than Papulacandin against their known target 1,3-beta-glucan synthase on the contrary, Papulacandin has high binding energy against all the other targets. It is highest against lanosterol $14 \alpha$-demethylase.

Table 5 Results of Caspofungin and Papulacandin against 1,3-beta-glucan synthase (known target) and others obtained from FireDock.

\begin{tabular}{lcccc}
\hline Drug & $\begin{array}{c}\text { 1,3-beta- } \\
\text { glucan } \\
\text { synthase } \\
\text { (Known) }\end{array}$ & $\begin{array}{c}\text { Chitn } \\
\text { synthase }\end{array}$ & Chitinase & $\begin{array}{c}\text { Lanosterol 14 } \\
\text { a-demethylase }\end{array}$ \\
\hline Caspofungin & -117.59 & -32.96 & -42.12 & -47.74 \\
Papulacandin & -67.32 & -37.88 & -44.93 & -61.54 \\
\hline
\end{tabular}

On analysis of the best docked structure of Papulacandin against lanosterol $14 \alpha$ demethylase (figure $7 \mathrm{c}$ ) it can be said that Papulacandin binds to the same place like all the other drugs binding to lanosterol $14 \alpha$-demethylase in its group (Ro091470 and Fluconazole) and may exhibit activity against it in in-vivo and invitro studies.

On analysis of table 6 it becomes clear that Ro- 091470 has a higher binding energy than fluconazole and also has the highest binding energy against all the other targets in its group and therefore might have a good multi-targeting efficiency. Ro-091470 has the highest binding energy against its known target 
lanosterol $14 \alpha$-demethylase which has already been analysed (figure 7d). The second highest binding energy was found to be against 1,3 beta glucan synthase.

Table 6 Results of Fluconazole and Ro-091470 against lanosterol $14 \alpha$ demethylase (known target) and others obtained from FireDock.

\begin{tabular}{lcccc}
\hline Drug & $\begin{array}{c}\text { Lanosterol 14 } \\
\text { a-demethylase } \\
\text { (Known) }\end{array}$ & $\begin{array}{c}\text { Chitin } \\
\text { synthase }\end{array}$ & Chitinase & $\begin{array}{c}\mathbf{1 , 3} \text { beta } \\
\text { glucan } \\
\text { synthase }\end{array}$ \\
\hline Fluconazole & -41.86 & -20.83 & -24.51 & -36.40 \\
Ro-091470 & -51.17 & -29.70 & -28.17 & -42.64 \\
\hline
\end{tabular}

On analysis of this docked structure it becomes clear that Ro-091470 binds to the same region like all the other drugs binding to 1,3-beta-glucan synthase in its group (Papulacandin and Caspofungin) as shown in figure $7 \mathrm{a}$

In the current study, it is also clear that most of the antifungals studied have a higher binding energy against the targets lanosterol $14 \alpha$-demethylase and 1,3 beta-glucan synthase as compared to the chitin and chitin synthase. This indicates that lanosterol $14 \alpha$-demethylase and 1,3-beta-glucan synthase are comparatively more suitable or better targets for the antifungals however, a wet lab validation is required.

\section{DISCUSSION}

Literature is full of reports containing information about drugs developed to aim at a single target. But according to the different studies conducted in the past, drugs which can aim at multiple targets are more succesful. Therefore, keeping this concept in mind present manuscript tests the activity of some known antifungals against their targets and also computes their efficiency to be used for multi-targeting. Henceforth, in the present study, we have tested the activity of some known antifungals against their targets and also computed their efficiency to be used for multi-targeting.

Argifin, a natural compound was reported to have a docking score of -7.557 $\mathrm{Kj} / \mathrm{mol}$ against chitinase computed through the Glide software by Roy and Mukherjee (2015) which has a similar trend (with respect to negative binding energy) to the data reported here which is $-28.59 \mathrm{Kcal} / \mathrm{mol}$. The negative binding energy shows that the reaction is spontaneous and the complex formed is stable. In another study, the Glide score, of Allosamidine against fungal chitinase was found to be -9.94 by Jeyam et al., (2014). This is also supported by present study where we got the binding energy value as -29.99 . There is no report on the determination of binding energy of Methylxanthin on fungal chitinase but according to a study by Tsirilakis et al. (2012), Cryptococcus neoformans and Aspergillus fumigatus have shown abnormal cell morphology on treatment with methylxanthin at a concentration between $0.5-10 \mathrm{mM}$. Schüttelkopf et al (2010) reported that although Acetozolamide and its analogues are weak inhibitors of fungal chitinase yet it has high ligand efficiency and can be used as a therapeutic agent in the future. Similarly, Amanda et al., (2012) has also reported that Acetozolamide affects the cell wall of Blastomyces dermatidis but could not observe any change in its growth curve. These results are in unanimity with the results of the current study that Acetozolamide has a binding energy that is comparatively lower than the binding energy it has against 1,3-beta-glucan synthase and lanosterol $14 \alpha$-demethylase.

Not much of the in-silico work has been published about chitin synthase. Obovatol has been found to have a good activity as a chitin synthase 2 inhibito against Saccharomyces cerevisiae (Hwang et al., 2002). In another study, Nikkomycin has been shown to affect chitin synthase 1 and 3 but no effect was found on chitin synthase 2 in case of Saccharomyces cerevisiae, however, in case of Candida albicans, Nikkomycin has shown to inhibit all the three isozymes of chitin synthase (Kim et al., 2002). Studies conducted on the structure-activity relationship (SAR) of polyoxins against chitin synthase suggests that Polyoxin L, has a weak inhibitory effect on chitin synthase most probable reason being absence of thymine which is assumed to be important for bioactivity (Li et al., 2012)

Papulacandins (A-E), contain benzannulated spiroketal unit which is the active part of many biological compounds. These antifungals have been reportedly showing high specific activity against yeasts, but have shown inertness against filamentous fungi, bacteria and protozoa (Traxler et al., 1977). In this study, Firedock was used to determine the in-silico activity of Caspofungin against 1,3 beta-glucan synthase and unlike the report of Jeyam et al., (2014) (-1.68 $\mathrm{Kcal} / \mathrm{mol})$, it was found to be $-60.65 \mathrm{Kcal} / \mathrm{mol}$.

Similarly, Ro-09-1470 showed high activity against Candida glabrata, Cryptococcus neoformans, Rhodotorula rubra, Trichosporon cutaneum, Aureobasidium pullulans, Exophiala dermatitidis and Exophiala jeanselmei and relatively less activity against Candida albicans, Candida tropicalis, Saccharomyces cerevisiae (Aoki et al, 1992). It is also known to interact with lanosterol $14 \alpha$-demethylase. The data presented in this manuscript supports the fact as the in-silico binding energy obtained is on the higher side i.e. -51.71 $\mathrm{Kcal} / \mathrm{mol}$. Vembu et al. (2014) has obtained a binding energy value -33.34 by performing docking of Fluconazole against lanosterol $14 \alpha$-demethylase by using Glide software. Likewise, in the present study we have obtained the binding energy value to be $-41.86 \mathrm{Kcal} / \mathrm{mol}$.

\section{CONCLUSION}

Current manuscript is a unique in-silico study aimed to identify the multitargeting efficiency of some antifungals currently being used. Four natural antifungals have also been screened for this approach of multi-targeting. It has been found that most of the studied antifungals exhibit multi-targeting efficiency but all of them have a higher binding affinity towards 1,3-beta-glucan synthase and lanosterol $14 \alpha$-demethylase. Moreover, amongst the natura antifungals, Argifin, Papulacandin and Ro-091470 have shown a high multi targeting efficiency and can be worked upon by the pharmaceutical companies by using them as scaffolds and designing new antifungals or enhancing their other properties so that they can be used as suitable antifungals in future. However, more wet lab experiments need to be performed in order to ascertain the activity of these antifungals against different targets.

Conflict of interest: Authors declare that there is no conflict of interest.

Acknowledgement: One of the authors Neelabh would like to thank Indian Council of Medicla Research (ICMR) for providing Senior Research Fellowship. Additionally, the authors would like to thank Principal, Mahila Mahavidyalaya, Banaras Hindu University, Varanasi for providing the laboratory facilities.

\section{REFERENCES}

Korcsmáros, T., Szalay, M. S., Böde, C., Kovács, I. A., \& Csermely, P. (2007). How to design multi-target drugs: target search options in cellular networks. Expert opinion on drug discovery, 2(6), 799-808.doi: https://doi.org/10.1517/17460441.2.6.799

Csermely, P., Agoston, V., \& Pongor, S. (2005). The efficiency of multi-target drugs: the network approach might help drug design. Trends in pharmacological sciences, 26(4), 178-182.doi: https://doi.org/10.1016/j.tips.2005.02.007

Tang, J., Karhinen, L., Xu, T., Szwajda, A., Yadav, B., Wennerberg, K., \& Aittokallio, T. (2013). Target inhibition networks: predicting selective combinations of druggable targets to block cancer survival pathways. PLoS computational biology, 9(9), e1003226.doi: https://doi.org/10.1371/journal.pcbi.1003226

Hartl, L., Zach, S., \& Seidl-Seiboth, V. (2012). Fungal chitinases: diversity, mechanistic properties and biotechnological potential. Applied microbiology and biotechnology, 93(2), 533-543.doi: https://doi.org/10.1007/s00253-011-3723-3

Henar, M. V., Durán, A., \& Roncero, C. (1999). Chitin synthases in yeast and fungi. Exs, 87, 55-69.doi: 10.1007/978-3-0348-8757-1 4

Liu, J., \& Balasubramanian, M. K. (2001). 1, 3-beta-Glucan synthase: a useful target for antifungal drugs. Current Drug Targets-Infectious Disorders, 1(2), 159 169.doi: https://doi.org/10.2174/1568005014606107

Becher, R., \& Wirsel, S. G. (2012). Fungal cytochrome P450 sterol $14 \alpha$ demethylase (CYP51) and azole resistance in plant and human pathogens. Applied microbiology and biotechnology, 95(4), 825-840. doi: https://doi.org/10.1007/s00253-012-4195-9

Hwang, E. I., Kwon, B. M., Lee, S. H., Kim, N. R., Kang, T. H., Kim, Y. T., et al. (2002). Obovatols, new chitin synthase 2 inhibitors of Saccharomyces cerevisiae from Magnolia obovata. Journal of Antimicrobial Chemotherapy, 49(1), 95-101. doi: https://doi.org/10.1093/jac/49.1.95

Aoki, Y., Yoshihara, F., Kondoh, M., Nakamura, Y., Nakayama, N., \& Arisawa M. (1993). Ro 09-1470 is a selective inhibitor of P-450 lanosterol C-14 demethylase of fungi. Antimicrobial agents and chemotherapy, 37(12), 26622667. doi: http://10.1128/AAC.37.12.2662

Mashiach, E., Schneidman-Duhovny, D., Andrusier, N., Nussinov, R., \& Wolfson, H. J. (2008). FireDock: a web server for fast interaction refinement in molecular docking. Nucleic acids research, 36(suppl_2), W229-W232. doi https://doi.org/10.1093/nar/gkn186

Neelabh, Jeswara, K., Kumari, A., Singh, K. (2015) In-silico designing of NKK A better ligand than Acyclovir against Herpes Simplex Virus. Indian J. Pharm 3: 48-55.doi not available

Neelabh \& Singh, K. (2018) From Natural products to therapeutically importan antifungals. Curent Trends in Biotechnology and Pharmacy, 12(2), 206-212. doi not available

Neelabh, Tirkey, N.N, Singh, K. (2018) In-silico and in-vitro studies on funga chitinase as a target enzyme for antifungal activity of closantel. Journal of Microbiology, Biotechnology and Food Sciences, 7:459-453. doi: $\underline{10.15414 / j m b f s .2018 .7 .5 .449-453}$

Roy, D., \& Mukherjee, K. (2015). Homology modeling and docking studies of human chitotriosidase with its natural inhibitors. Journal of Proteins \& Proteomics, 6(2).doi not available

Jeyam, M., Arangaraj, M., Ravikumar, P., \& Shalini, G. (2014). Computational analysis of phytocompounds with 1, 3- $\beta$-D-Glucan synthase for antidermatophytic activity. doi: 10.7324/JAPS.2014.40211

Tsirilakis, K., Kim, C., Vicencio, A. G., Andrade, C., Casadevall, A., \& Goldman, D. L. (2012). Methylxanthine inhibit fungal chitinases and exhibit $\begin{array}{llll}\text { antifungal activity. } & \text { Mycopathologia, } & 173(2-3), & 83-91 .\end{array}$ doi:https://doi.org/10.1007/s11046-011-9483-x 
Schüttelkopf, A. W., Gros, L., Blair, D. E., Frearson, J. A., van Aalten, D. M., \& Gilbert, I. H. (2010). Acetazolamide-based fungal chitinase inhibitors Bioorganic \& medicinal chemistry, 18(23), 8334-8340. doi https://doi.org/10.1016/j.bmc.2010.09.062

Searle, A. J., Winston, V., \& Scalarone, G. M. (2012). Blastomyces dermatitidis: Chitinase Homology Model, in Silico Docking, and Inhibition Assay. Open Journal of Medical Microbiology, 2(1), $1 . \quad$ doi http://dx.doi.org/10.4236/ojmm.2012.21001

Kim, M. K., Park, H. S., Kim, C. H., Park, H. M., \& Choi, W. (2002). Inhibitory effect of nikkomycin Z on chitin synthases in Candida albicans. Yeast, 19(4), 341-349. doi: https://doi.org/10.1002/yea.837.

Li, J., Li, L., Feng, C., Chen, Y., \& Tan, H. (2012). Novel polyoxins generated by heterologously expressing polyoxin biosynthetic gene cluster in the sanN inactivated mutant of Streptomyces ansochromogenes. Microbial cell factories, 11(1), 135. doi: https://doi.org/10.1186/1475-2859-11-135

Traxler, P., Gruner, J., \& Auden, J. A. L. (1977). Papulacandins, a new family of antibiotics with antifungal activity. The Journal of antibiotics, 30(4), 289296.doi: https://doi.org/10.7164/antibiotics.30.289

Aoki, Y., Yamazaki, T., Kondoh, M., Sudoh, Y., Nakayama, N., Sekine, Y. \& Arisawa, M. (1992). A new series of natural antifungals that inhibit P450 lanosterol C-14 demethylase. The Journal of antibiotics, 45(2), 160-170.doi https://doi.org/10.7164/antibiotics.45.160

Vembu, S., Parasuraman, P., \& Gopalakrishnan, M. (2014). Design, in silico molecular docking studies, synthesis, spectral characterization and in vitro antifungal evaluation of 1-(4-(1H-tetrazole-1-yl) phenyl)-3-arylprop-2-en-1-ones. Der Phar 